\title{
Nova lei brasileira de migração: avanços, desafios e ameaças
}

\author{
Antônio Tadeu Ribeiro de Oliveira*
}

As políticas migratórias no Brasil viviam o paradoxo de conviver com um marco regulatório baseado na segurança nacional em plena ordem democrática. Além de ultrapassado na dimensão política, o Estatuto do Estrangeiro engessava a tomada de decisões voltadas ao acolhimento e à integração dos imigrantes. Nas últimas décadas do século XX e na década corrente, a saída de brasileiros para residirem no exterior e a chegada de fluxos migratórios de diversas origens tornavam imperiosa a revisão do arcabouço legal. 0 presente artigo aborda os antecedentes que levaram à elaboração e aprovação da nova lei de migração e destaca os avanços alcançados, chamando a atenção para os desafios e ameaças a serem enfrentados de forma a assegurar a efetiva implementação da nova ordem jurídica.

\section{Antecedentes}

A migração internacional no Brasil era regulada até então por normas legais implementadas no período do Regime Militar, nas quais o imigrante era visto como uma ameaça à “estabilidade e à coesão social" do país, predominando, portanto, o enfoque da segurança nacional, que deveria manter de fora das nossas fronteiras aqueles que "pretendiam vir causar desordem em nossas plagas".

A Lei n. 6.815/1980, que estabeleceu esse conjunto de normas, também criou o Conselho Nacional de Imigração (CNIg), o qual manteve em prática, num cenário de baixa pressão imigratória, a política do mobilizar, selecionar e localizar, que desde sempre predominou nas políticas migratórias implementadas no país (VAINER, 2000), seguindo a lógica de atender às demandas por força de trabalho estrangeira.

Ocorre que, a partir dos anos 1980, a questão migratória voltou a ter alguma relevância na agenda política e social brasileira, em que, entre outros aspectos, destacam-se: a emergência, naquela década, da emigração internacional, pois brasileiros passaram a viver no exterior em situação de vulnerabilidade e não vislumbravam as mínimas condições

\footnotetext{
* Instituto Brasileiro de Geografia e Estatística (IBGE), Observatório das Migrações Internacionais, Rio de Janeiro-RJ, Brasil (tadeu.cidade@gmail.com)
} 
que favorecessem uma possível reinserção no país, como, por exemplo, aspectos relacionados à obtenção de trabalho e à cobertura da previdência social; a entrada irregular de trabalhadores e suas famílias que vieram, sobretudo, da Bolívia e Paraguai; e a chegada massiva de haitianos e africanos, no início dos anos 2010. Tudo isso escapava ao controle do governo brasileiro e requeria uma tomada de posição, dado que o aparato legal não conseguia dar conta de enfrentar todas essas situações.

Tais questões foram sendo tratadas de duas maneiras. Na primeira, seguiu-se a receita dos Estados Unidos e da União Europeia, promovendo a regularização dos estrangeiros que residiam há determinado tempo no país. Essa medida, tomada tanto no governo autocrático quanto nos democráticos, ${ }^{1}$ nem conseguia atender/satisfazer a todos que se encontravam nessa situação, nem resolvia o essencial - a necessidade de uma política migratória clara, que abarcasse, ao menos, os eixos da regulação, integração e cooperação internacional, seja qual fosse o viés ideológico que orientasse tais políticas. Na segunda, o CNIg passou a enfrentar o problema emitindo, pontualmente, Resoluções Normativas para cada questão surgida. Não obstante avanços importantes ${ }^{2}$ em aspectos humanitários, proteção, livre circulação dos trabalhadores do Mercosul, entre outros, o que se produziu foi um verdadeiro emaranhado normativo, que, da mesma forma, está longe de afrontar as questões migratórias com a necessidade e a profundidade requeridas. Deve-se enfatizar que, nesse ínterim, o país também aderiu a medidas internacionais que visam a proteção e garantias dos direitos dos imigrantes, como na questão da Convenção Contra o Crime Organizado e o Tráfico de Pessoas, em 2004 (SPRANDEL, 2012).

Assim, o tratamento das questões relacionadas às migrações internacionais vinha navegando num mar de avanços, paralisia e retrocessos, como, por exemplo, a não assinatura da Convenção 97 das Nações Unidas, sobre o direito dos trabalhadores migrantes e suas famílias (MARINUCCI, 2012). Nesse sentido, a aparente "não política migratória” seria a manutenção, em grande medida, das práticas herdadas do regime de exceção.

[...] é falso pensar que o Brasil não possui uma política migratória. Evidente que ele não possui uma política restritiva, de controle ostensivo de fronteira, como é o caso da Europa e dos Estados Unidos. No entanto, embora fragmentada, opaca e casuística, nossa política existe, e garante a mesma discricionariedade absoluta do Estado da época da ditadura. (VENTURA, 2014)

Contudo, é importante reconhecer que a relevância alcançada pelo debate em torno da questão migratória no Brasil impulsionava e pressionava na direção dos avanços necessários, o que levaria a embates de posições e ideologias conflitivas (PATARRA, 2012). Do governo central eram emitidos sinais distintos na forma de abordar a problemática. $A$

\footnotetext{
${ }^{1}$ Patarra (2012) menciona as anistias concedidas em 1981, 1988 e 1998, além do Decreto n. 6.893/2009 que promoveu a regularização de imigrantes que viviam de forma irregular no país.

2 Sprandel (2012) destaca a Resolução Normativa n. 93/2010, que disciplina a concessão de visto permanente ou permanência no Brasil a estrangeiro considerado vítima do tráfico de pessoas, e a Resolução Normativa n. 77/2008, que dispõe sobre critérios para a concessão de visto temporário ou permanente, ou de autorização de permanência, ao companheiro ou companheira, em união estável, sem distinção de sexo.
} 
Secretaria de Assuntos Estratégicos (SAE) buscava alterar a lei de migrações com enfoque na atração de força de trabalho qualificada. Seriam, preferencialmente, engenheiros, médicos e profissionais do setor de alta tecnologia. A ideia era que essa mão de obra viesse ajudar a impulsionar o desenvolvimento e crescimento econômico (EL UNIVERSAL, 2014; BRASIL, 2012). Já a Secretaria Nacional de Justiça (SNJ) procurava modificar a lei a partir do paradigma das garantias dos direitos dos migrantes, tendo inclusive constituído uma Comissão de Especialistas que elaborou um Anteprojeto de Lei de Migrações e Promoção dos Direitos dos Migrantes no Brasil. Esse Anteprojeto passou pela avaliação da sociedade civil, na I Conferência Nacional sobre Migrações e Refúgio (Comigrar), realizada em 2014, e foi encaminhado à Presidência da República, de modo a ser submetido à discussão e aprovação do Congresso Nacional (BRASIL, 2014). 0 CNIg, por sua vez, apresentou um Projeto de Lei que também procurava assegurar garantias e direitos dos migrantes. Diante desse conjunto de iniciativas oriundas do Poder Executivo, o governo federal procurou ter uma atuação unificada, buscando algum consenso em torno do Projeto de Lei do Senado (PLS) 288/2013, elaborado pelo senador Aloysio Nunes e relatado pelo senador Ricardo Ferraço.

Essas visões nortearam as discussões e disputas sobre as migrações internacionais e se refletiram nas propostas de leis e normatizações que, além do Anteprojeto patrocinado pelo MJ/SNJ e do Projeto de Lei apresentado pelo CNIg, surgiram no PLS n. 288/2013 e no Projeto de Lei n. 5.565/2009, que tramitavam no Congresso Nacional.

O PL n. 5.565/2009, que se arrastava desde de 2005, só em 2009 foi encaminhado pelo governo ao Congresso Nacional. Sprandel (2012) assinala que, apesar de alguns avanços, esse instrumento ainda era tímido e restritivo. O PL mantinha, no essencial, a política migratória praticada no Brasil, baseada no mobilizar, classificar e localizar, refletia mais o enfoque que trata de forma instrumental as migrações internacionais, procurando tirar proveito das vantagens econômicas e, apesar de ser apresentado como um novo instrumento baseado nas garantias dos direitos humanos dos migrantes, mantinha algumas características típicas da visão fundada na segurança nacional.

Já o PLS n. 288/2013 foi apresentado ao Senado Federal com a proposta de: fazer avançar o estatuto jurídico da questão migratória na direção das garantias e dos direitos; assegurar a plena integração dos imigrantes; implementar a cooperação internacional; combater o tráfico de pessoas; e contemplar a questão dos emigrantes. Além disso, em sua justificação, o senador Aloysio Nunes assinalava, entre outros aspectos, que não tratou as questões ligadas à extradição por entender que essas devem ser objeto de uma discussão mais ampla no âmbito da cooperação penal internacional; apontava a defesa da concessão de direitos políticos aos imigrantes na esfera municipal, tendo inclusive nesse sentido encaminhado a Proposta de Emenda Constitucional no 25/2012; e que, dada a relevância adquirida pela questão migratória, deveriam ser repensados os papéis do Ministério das Relações Exteriores, Ministério da Justiça, Polícia Federal, Ministério do Trabalho e Emprego e do próprio CNIg, e se criar uma Agência Nacional de Migração, fundada numa nova lei federal de migração. 
O substitutivo do relator, senador Ricardo Ferraço, elaborado a partir do consenso possível obtido junto aos órgãos do Executivo que lidam com as questões migratórias, se, por um lado, eliminou a cláusula restritiva do PLS original, que incentivava a admissão de força de trabalho especializada, por outro, introduziu um problema sério, pois, ao revogar a Lei n. 6.815/1980, acabava com o Conselho Nacional de Imigração sem criar ou fazer menção à necessidade de um órgão gestor das políticas migratórias. 0 substitutivo foi aprovado por unanimidade no Senado Federal e encaminhado para tramitação na Câmara dos Deputados.

Após tramitar na Câmara dos Deputados, sob o número de Projeto de Lei 2.516, e ter sofrido algumas mudanças, como a reintrodução de artigos menos restritivos aos imigrantes e a criação do Conselho Nacional sobre Migração (CMIg), em substituição ao CNIg, o projeto teve que retornar ao Senado Federal para ser reapreciado pelos senadores, para finalmente ser aprovado e encaminhado à sanção presidencial.

\section{A nova lei}

Em 24 de maio do corrente ano, o presidente da República sancionou a nova lei de migração, a Lei n. 13.445/2017 (BRASIL, 2017). Contudo, é importante ressaltar que a sanção presidencial veio acompanhada de 20 vetos. No momento que este texto estava sendo redigido, o Senado Federal apreciava os vetos presidenciais, podendo derrubá-los, evento pouco provável. 0 prazo para que a Lei entre em vigor é de 180 dias.

Apesar dos vetos, cabe destacar que o novo arcabouço legal representa um grande avanço no trato da questão migratória no Brasil e abre a perspectiva de esperança para os coletivos migrantes que já se encontram por aqui, para aqueles que estão por vir e para os brasileiros que emigraram para o exterior. 0 maior avanço de todos, sem dúvida, foi acabar com o anacronismo do Estatuto dos Estrangeiros, aparato jurídico inspirado num regime de exceção, cuja base se assentava na doutrina da segurança nacional e que vigorava mesmo depois da aprovação da Constituição Democrática de 1988, que, entre outros objetivos, se colocava como missão sepultar os resquícios jurídicos da ditadura militar.

0 avanço mais geral reside na mudança de enfoque desse novo marco legal das migrações, agora com ênfase na garantia dos direitos das pessoas migrantes, tanto dos estrangeiros que por aqui aportam quanto para os brasileiros que vivem no exterior.

Entre as conquistas obtidas com a nova lei, destacam-se os dispositivos previstos nos

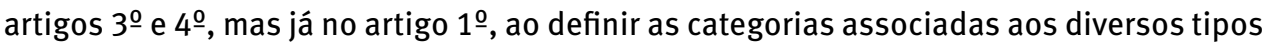
de mobilidade, a Lei n. 13.445 cria as categorias imigrante, já com a modulação do tempo de permanência - temporários ou permanentes; emigrante, demonstrando a preocupação com os brasileiros residentes no exterior; visitante, para os casos de curtíssima duração; e estabelece a definição de apátrida, facilitando a acolhida de um número crescente de pessoas que vêm perdendo sua nacionalidade. 
No artigo 3ำ, que trata dos princípios e diretrizes da política migratória brasileira, destacam-se, entre outros, os seguintes pontos: a universalidade, indivisibilidade e interdependência dos direitos humanos; o repúdio e prevenção à xenofobia, ao racismo e a quaisquer formas de discriminação; a não criminalização da migração; a não discriminação em razão dos critérios ou dos procedimentos pelos quais a pessoa foi admitida em território nacional; a promoção de entrada regular e de regularização documental; a acolhida humanitária; a garantia do direito à reunião familiar; a igualdade de tratamento e de oportunidade ao migrante e a seus familiares; a inclusão social, laboral e produtiva do migrante por meio de políticas públicas; o acesso igualitário e livre do migrante a serviços, programas e benefícios sociais, bens públicos, educação, assistência jurídica integral pública, trabalho, moradia, serviço bancário e seguridade social; a promoção e difusão de direitos, liberdades, garantias e obrigações do migrante; a cooperação internacional com Estados de origem, de trânsito e de destino de movimentos migratórios, a fim de garantir efetiva proteção aos direitos humanos do migrante; a proteção integral e atenção ao superior interesse da criança e do adolescente migrante; a proteção ao brasileiro no exterior; a promoção do reconhecimento acadêmico e do exercício profissional no Brasil, nos termos da lei; e o repúdio a práticas de expulsão ou de deportação coletivas.

0 artigo $4^{\circ}$, voltado a estabelecer garantias aos migrante, assegura: direitos e liberdades civis, sociais, culturais e econômicos; direito à liberdade de circulação em território nacional; direito à reunião familiar do migrante com seu cônjuge ou companheiro e seus filhos, familiares e dependentes; medidas de proteção a vítimas e testemunhas de crimes e de violações de direitos; direito de transferir recursos decorrentes de sua renda e economias pessoais a outro país, observada a legislação aplicável; direito de reunião para fins pacíficos; direito de associação, inclusive sindical, para fins lícitos; acesso a serviços públicos de saúde e de assistência social e à previdência social, nos termos da lei, sem discriminação em razão da nacionalidade e da condição migratória; direito à educação pública, vedada a discriminação em razão da nacionalidade e da condição migratória; garantia de cumprimento de obrigações legais e contratuais trabalhistas e de aplicação das normas de proteção ao trabalhador, sem discriminação em razão da nacionalidade e da condição migratória; direito de sair, de permanecer e de reingressar em território nacional, mesmo enquanto pendente pedido de autorização de residência, de prorrogação de estada ou de transformação de visto em autorização de residência; e direito do imigrante de ser informado sobre as garantias que lhe são asseguradas para fins de regularização migratória.

Enfim, não obstante alguns vetos inspirados em visões que defendem medidas restritivas, o país passa a ter uma das legislações mais modernas no trato das políticas migratórias, avançando no tratamento dos pilares que sustentam a integração plena do migrante à sociedade brasileira ao assegurar o pleno acesso aos serviços, garantindo a reunião familiar, reconhecendo a formação acadêmica obtida no exterior, permitindo a associação sindical e política, facilitando a inclusão laboral, repudiando práticas de discriminação e descriminalizando a migração e repudiando práticas de deportações coletivas. 
No plano da cooperação internacional, apesar de o país já possuir uma legislação moderna na questão do refúgio - a Lei n. 9.474/1997 (BRASIL, 1997) - e já vir adotando políticas de acolhimento humanitário, como no caso dos haitianos, ter incluído expressamente na nova lei o dispositivo que permite a concessão desse tipo de visto foi fundamental. Ademais, a facilitação das remessas, a proteção aos brasileiros residentes no exterior, a cooperação com os Estados de origem, trânsito e destino buscando a proteção dos direitos do migrante e o fortalecimento da integração econômica, política, social e cultural dos povos da América Latina são medidas protetivas importantíssimas e que fazem com que avance o trato das questões migratórias nas relações com os demais países envolvidos nessa temática.

\section{Desafios e ameaças}

Os principais desafios colocados dizem respeito à regulamentação da Lei e ao enfretamento dos vetos colocados pela Presidência da República, pois, embora minoritários, os setores conservadores são suficientemente bem articulados para poderem atuar no sentido de desconfigurar alguns aspectos positivos no processo de regulamentação. Assim, o espectro da sociedade civil que defende a nova lei deve estar atento para assegurar que o marco legal reflita os anseios por garantir direitos e proteção à pessoa migrante. Além disso, é extremamente necessária a definição do organismo de governo que se incumbirá de conduzir as políticas migratórias no país.

O Ministério do Trabalho, por meio do Conselho Nacional de Imigração (CNIg), já constituiu Grupo de Trabalho para tratar da regulamentação. Os membros do GT são os próprios conselheiros e conselheiras do CNIg, o que garante a participação da sociedade civil no debate. A Secretaria Nacional de Justiça (SNJ), do Ministério da Justiça e Segurança Pública, parece que também vai atuar na regulamentação, mas, até o momento, não se sabe ao certo quais procedimentos a SNJ irá adotar.

Em relação aos vetos, aqueles que causaram maiores prejuízos foram os propostos por:

- Casa Civil, que logo no Inciso I do $\S 1^{0}$ do art. $1^{0}$ vetou a definição de migrante sob o argumento de que o conceito estava demasiadamente amplo ao incluir o imigrante, 0 emigrante, o residente fronteiriço e o apátrida. Também vetou o parágrafo $4 \%$ do art. 113, que colocava como grupo vulnerável a pessoa que responde em liberdade por algum delito cometido. Esses vetos revelam, por um lado, a falta de conhecimento das várias dimensões da mobilidade humana e, por outro, a insensibilidade ao não reconhecer que uma pessoa que responde por processo criminal num país estranho, seja qual for o motivo, encontra-se em enorme vulnerabilidade. 0 atenuante a favor da necessária aprovação do dispositivo reside no fato de a pessoa estar em liberdade, o que sinaliza tratar-se de delito de menor poder ofensivo;

- Ministério da Justiça e Segurança Pública, Advocacia Geral da União e do Gabinete de Segurança Institucional, de onde partiram vetos igualmente prejudiciais, como: 
o que não garante a livre circulação aos povos originários, alegando afronta à soberania nacional; o que impede a revogação das expulsões decretadas antes de 1988, ou seja, aquelas baseadas no regime de exceção, também sob o argumento que isso afetaria a soberania nacional; o que ampliava a autorização de trabalho, sem a necessidade de autorização específica, cuja justificativa foi a necessária referência específica via norma; e o veto integral ao artigo que concedia anistia aos migrantes em situação irregular que tivessem ingressado no território nacional até julho de 2016. A justificativa dada é muito frágil, uma vez que se ampara no fato de existirem diversos status migratórios que seriam beneficiados e por não ser possível precisar a data de entrada da pessoa em situação irregular.

Os vetos originários no MJSP, na AGU e no Gabinete de Segurança Institucional revelam as contradições e as disputas colocadas ao longo de todos esses anos em que se buscou um novo aparato jurídico para as políticas migratórias, reveladas pela presença na esfera de governo de setores, ainda com expressão política, que: consideram as migrações uma questão de segurança, daí o discurso da soberania nacional; veem no migrante uma ameaça ao mercado de trabalho dos nacionais; e não conseguem compreender que é muito mais fácil lidar com migrações regulares, sobretudo quando se tem preocupação exacerbada com segurança e controle.

Além desses desafios, um outro, revestido de ameaça, é a crescente manifestação organizada de segmentos sociais, assumidamente com posições à direita do campo ideológico, que são contrários à nova lei. São pessoas completamente equivocadas a respeito das migrações internacionais e que sequer se dão ao mínimo trabalho de conhecer o tema, pois se o fizessem teriam a dimensão do quanto são equivocadas suas posições, uma vez que uma vasta gama de trabalhos acadêmicos sérios ${ }^{3}$ mostra que a migração traz mais benefícios do que prejuízos para os países de destino.

Embora em número reduzido, tais segmentos emanam sinais que levam a atitudes preconceituosas, racistas e até mesmo xenófobas, o que deve ser combatido por meio de campanhas educativas e com o poder de polícia naquelas situações mais graves.

\section{Considerações finais}

Nas últimas décadas do século XX e na década corrente estão sendo observadas profundas alterações, em escala internacional, no comportamento do fenômeno migratório no Brasil. Essas mudanças, verificadas tanto na chegada de imigrantes, acompanhada da diversificação dos lugares de origem, quanto na continuada saída de brasileiros, apontavam para necessária atualização do arcabouço jurídico que sustentasse nossas políticas migratórias, tornando imperioso o sepultamento do Estatuto do Estrangeiro.

\footnotetext{
$\overline{3}$ Entre esses trabalhos, podem ser destacados Martine (2005), Patarra (2006) e Barricarte (2010).
} 
Muito embora não seja uma "lei dos sonhos", a sociedade brasileira, em particular imigrantes e emigrantes, tem muito a comemorar, dado que, mesmo com os vetos presidenciais de última hora, avanços fundamentais para garantias de direitos e proteção da pessoa migrante foram colocados em vários dos dispositivos da nova lei.

Contudo, ainda há muito a se fazer! Os próximos passos apontam nas seguintes direções: assegurar que a regulamentação preserve esses avanços e que a lei não seja desfigurada nesse processo; reivindicar a imediata definição do organismo de governo que será responsável pela condução das políticas migratórias; buscar reverter de alguma forma os vetos presidenciais, sobretudo aqueles que atingiram os povos indígenas e o que negou anistia aos migrantes que se encontram em situação irregular; e promover campanhas educativas e de esclarecimentos sobre a necessária implementação da lei, de modo a combater, no campo das ideias, os setores contrários à migração, o que não significa diminuir a atenção sobre possíveis atitudes mais agressivas, que irão requerer denúncia junto às autoridades policiais.

O desafio maior é seguir avançando, com uma conquista de cada vez, como, por exemplo, na aprovação pela Comissão de Constituição e Justiça do Senado do projeto de lei que prevê a participação de migrantes nas eleições municipais, desde que haja reciprocidade com os países de origem e na propositura do Projeto de Lei do deputado Orlando Silva (SP), que busca contornar o veto presidencial à anistia aos imigrantes que se encontram em situação irregular e ingressaram no país até 2016 (BRASIL, 2017).

A caminhada não será diferente do que foi até aqui, as disputas seguirão polarizadas, mas o passo maior já foi dado com a aprovação da lei na qual predomina o enfoque nos direitos humanos.

\section{Referências}

BARRICARTE, J. J. S. Socioeconomía de las migraciones em um mundo globalizado. Madrid: Editorial Biblioteca Nueva, 2010.

BRASIL. Câmara dos Deputados. Projeto de Lei 7.876, de 13 de junho de 2017. Brasília, 2017. Disponível em: «www.camara.gov.br/proposicoesWeb/fichadetramitacao?idProposic $\mathrm{ao}=2141497\rangle$. Acesso em: 21 jun. 2017.

Senado Federal. Lei 13.445, de 24 de maio de 2017. Brasília, 2017. Disponível em: 〈http://www2.camara.leg.br/legin/fed/lei/2017/lei-13445-24-maio-2017-784925publicacaooriginal-152812-pl.html〉. Acesso em: 18 jun. 2017.

Ministério da Justiça. Anteprojeto de Lei de Migrações e Promoção dos Direitos dos Migrantes no Brasil. Brasília, 2014. Disponível em: 〈http://library.fes.de/pdf-files/bueros/ brasilien/10947.pdf〉. Acesso em: 15 jan. 2015.

Secretaria de Assuntos Estratégicos. Grupo de Trabalho. Brasília: SAE, 25 de julho 2012. Disponível em: 〈http://www.sae.gov.br/site/?page_id=19845〉. Acesso em: 22 ago. 2014.

Presidência da República. Lei 9.474, de 22 de julho de 1997. Brasília, 1997. Disponível em: 〈www.planaltto.gov.br/ccivil/leis/L9474.htm〉. Acesso em: 21 jun. 2017. 
DUSEK, A. Comissão do Senado aprova permissão para estrangeiro participar de eleições. Estadão, 14 jun. 2017. Disponível em: 〈http://politica.estadao.com.br/noticias/geral,comissaodo-senado-aprova-permissao-para-estrangeiro-participar-de-eleicoes,70001840831〉. Acesso em: 18 jun. 2017.

EL UNIVERSAL. En Brasil cambiarán ley migratoria para impulsar ingreso de profesionales, 16 jan. 2014. Disponível em: 〈http://www.eluniversal.com/internacional/140116/en-brasil-cambiaranley-migratoria-para-impulsar-ingreso-de-profesiona〉. Acesso em: 15 jan. 2015.

MARINUCCI, R. Paradigmas de políticas migratórias e o Brasil. Brasília: CSEM, maio de 2012.

MARTINE, G. A globalização inacabada: migrações internacionais e pobreza no século 21. São Paulo em Perspectiva, v. 19, n. 3, p. 3-22, jul./set. 2005. Disponível em: 〈http://dx.doi. org/10.1590/S0102-88392005000300001〉. Acesso em: 21 jun. 2017.

PATARRA, N. L. O Brasil: país de imigração? Revista e-metropolis, ano 3, n. 9, p. 6-18, jun. 2012.

. Migrações internacionais: teorias, políticas e movimentos sociais. Estudos Avançados, v. 20, n. 57, maio/ago. 2006. Disponível em: 〈http://www.scielo.br/cgi-bin/wxis.exe/ $\mathrm{iah} /$ ? IsisScript=iah/iah. $x$ is\&base $=$ article $\% 5$ Edlibrary\&format $=i$ so. $p f t \& l a n g=i \&$ nextAction $=$ ln k\&indexSearch=AU\&exprSearch=PATARRA,+NEIDE+LOPES〉. Acesso em: 21 jun. 2017.

SPRANDEL, M. A. Políticas migratórias no Brasil do século XXI. In: SEMINÁRIO INTERNACIONAL DESLOCAMENTOS, DESIGUALDADES E DIRETOS HUMANOS. Anais... São Paulo, 6 e 7 de julho de 2012.

VAINER, C. B. Estado e migrações no Brasil: anotações para uma história de políticas migratórias. Revista Travessia, n. 36, p. 15-32, jan./abr. 2000.

VENTURA, D. Política migratória brasileira é obsoleta e dificulta vida de estrangeiros. UOL Notícias, 03 de maio de 2014. Disponível em: 〈http://noticias.uol.com.br/opiniao/coluna/2014/05/03/ politica-migratoria-brasileira-deixa-estrangeiros-em-situacao-precaria.htm . Acesso em: 16 jan. 2015.

\section{Sobre o autor}

Antônio Tadeu Ribeiro de Oliveira é doutor em Demografia, pesquisador do IBGE e pesquisador associado do Observatório das Migrações Internacionais.

\section{Endereço para correspondência}

Rua Maria Quitéria, 32 apto. 202, Ipanema

22410-040 - Rio de Janeiro-RJ, Brasil 
